\title{
POSTERIOR VERSUS ANTERIOR APPROACH TO TOTAL HIP ARTHROPLASTY: A SYSTEMATIC REVIEW AND META- ANALYSIS OF RANDOMIZED CONTROLLED TRIALS
}

\section{VIA POSTERIOR VERSUS VIA ANTERIOR PARA ARTROPLASTIA TOTAL DO QUADRIL: REVISÃO SISTEMÁTICA E METANÁLISE DE ESTUDOS CLÍNICOS RANDOMIZADOS}

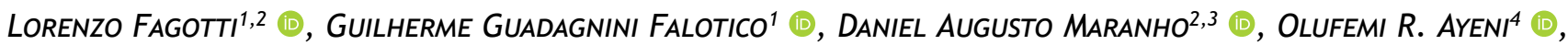 \\ BENNO EJNISMAN ${ }^{1}$ (D), MOISES COHEN ${ }^{1}$ (1), DIEGo COSTA ASTUR ${ }^{1}$ (1) \\ 1. Universidade Federal de São Paulo, Department of Orthopedics and Traumatology, Sports Traumatology Center (CETE), São Paulo, SP, Brazil. \\ 2. Hospital Sírio-Libanês, Brasília, DF, Brazil. \\ 3. University of São Paulo, Ribeirão Preto Medical School, Ribeirão Preto, SP, Brazil \\ 4. Division of Orthopaedic Surgery, McMaster University, Hamilton, Canada.
}

\section{ABSTRACT}

Objective: To perform a systematic review and meta-analysis to compare clinical and surgical outcomes of posterior versus anterior approach to primary total hip arthroplasty (THA). Methods: This study followed the standard methodology established by the Cochrane Handbook and the Preferred Reporting Items for Systematic Reviews and Meta-Analyses (PRISMA) guidelines. Two independent reviewers searched for randomized controlled trials comparing posterior an anterior approach to primary THA with at least one quantifiable functional outcome published in the PubMed, Cochrane, and Virtual Health Library databases. Results: The analysis included ten randomized controlled trials conducted with 774 patients. The posterior approach was associated with shorter operative time (mean of 15.98 minutes shorter, 95\% Cl 11.21 to 20.76, $p<0.00001$ ) while the anterior approach was associated with shorter length of hospital stay $(0.31$ days or about eight hours shorter, $95 \% \mathrm{Cl} 0.12$ to $0.51, \mathrm{p}=0.002$ ) and greater earlier improvement in functional outcomes up to six months from the procedure (mean Harris Hip Score of 4.06 points greater, $95 \% \mathrm{Cl} 2.23$ to 5.88, $\mathrm{p}<0.0001$ ). Conclusion: Whereas the posterior approach to primary THA is associated with a shorter operative time, the anterior approach has the potential to decrease the length of stay and provide greater short-term functional restoration. Level of evidence I, Systematic Review and Meta-Analysis.

Keywords: Hip. Arthroplasty, Replacement, Hip. Treatment Outcome. Complications. Meta-Analysis. Systematic Review.

\section{RESUMO}

Objetivo: Realizar uma revisão sistemática e metanálise para comparar os resultados clínicos e cirúrgicos entre a via posterior e via anterior para ATQ. Métodos: Este estudo seguiu as diretrizes Cochrane e PRISMA (Principais Itens para Relatar Revisões Sistemáticas e Meta-Análises). Dois investigadores independentes procuraram estudos randomizados controlados nas plataformas de busca PubMed, Cochrane e Biblioteca Virtual em Saúde. Estudos comparando a via posterior com a via anterior para ATQ primária com pelo menos um escore funcional de resultado clínico foram incluídos. Resultados: Dez estudos com 774 pacientes foram incluídos. A via posterior foi associada a um tempo operatório menor (média de 15.98 minutos menor, IC 95\% 11.21 a 20.76, $p<0.00001$ ), enquanto a via anterior foi associada a um tempo de internação hospitalar menor (0.31 dia ou cerca de oito horas a menos, IC 95\% 0.12 a 0.51, $p=0.002$ ) e melhora superior dos resultados funcionais em até seis meses após a cirurgia (Harris Hip Score médio de 4.06 pontos maior, IC 95\% 2.23 a 5.88, $p<0.0001)$. Conclusão: A via posterior foi associada a um tempo operatório menor, enquanto a via anterior tem o potencial de diminuir o tempo de hospitalização e fornecer melhor recuperação funcional no curto prazo. Nível de Evidência I, Revisão Sistemática e Metanálise.

Descritores: Artroplastia do Quadril. Resultados de Tratamento. Complicações, Metanálise. Revisão Sistemática.

Citation: Fagotti L, Falotico GG, Maranho DA, Ayeni OR, Ejnisman B, Cohen M, Astur DC. Posterior versus anterior approach for total hip arthroplasty: a systematic review and meta-analysis of randomized controlled trials. Acta Ortop Bras. [online]. 2021;29(6):297-303. Available from URL: http://hww.scielo.br/aob.

\section{INTRODUCTION}

When it comes to performing total hip arthroplasty (THA), there are controversies between anterior and posterior approach. Whereas the posterior is the most traditional and popular approach worldwide, ${ }^{1,2}$ the anterior approach has gained prominence during the second half of the 20th century with the contributions of

All authors declare no potential conflict of interest related to this article.

The study was conducted at the Universidade Federal de São Paulo, Department of Orthopedics and Traumatology, Sports Traumatology Center (CETE). Correspondence: Lorenzo Fagotti. Rua Napoleão de Barros, 715, Vila Clementino, São Paulo, SP, Brazil, 04024000. lorenzo fagotti@hotmail.com 
Smith-Petersen. ${ }^{3,4}$ The number of studies comparing different approaches and techniques for THA has increased in recent years, with a recent study highlighting the controversies over the evidence for clinical outcomes and economic factors favoring the anterior approach. ${ }^{5}$ However, high-quality evidence evaluating the potential superiority of one method over another is limited. Considering that, this systematic review and meta-analysis of randomized controlled trials (RCTs) aimed to compare postoperative functional outcomes and complication rates following primary THA through the posterior and anterior approach, as well as to identify which approach was associated with shorter operative time and length of hospital stay, lower level of postoperative opioid use and pain, and shorter time to discontinuing walking aids.

\section{METHODS}

This study followed the standard methodology established by the Cochrane Handbook and the Preferred Reporting Items for Systematic Reviews and Meta-Analyses (PRISMA) guidelines. ${ }^{6,7}$ The databases PubMed, Cochrane Library, and Virtual Health Library were searched for articles indexed up to June $2^{\text {nd }}, 2020$, using the terms "total hip arthroplasty", "posterior" and "anterior" in combination with "comparison of approaches". All RCTs comparing the posterior (control group) and the anterior approach to THA, with at least one quantifiable clinical outcome measured by a validated score (Table 1) were considered eligible. Articles were selected by two independent reviewers, whom also screened their titles and abstracts for eligibility criteria. After that, studies were fully read for exclusion criteria, which included: narrative review articles; biomechanical, animal, or cadaveric studies; investigations conducted with children; studies using double-incision approaches; studies reporting data from arthroplasty registries; studies on bilateral THA; studies involving surgical revision of failed primary hip arthroplasty or hemiarthroplasty; and studies with no abstract or written in non-English languages. Eventual disagreements between the two reviewers were solved by a third reviewer.

\begin{tabular}{|c|c|}
\hline Domain (order) & Inclusion criterion \\
\hline Study design (1) & $\begin{array}{l}\text { Study comparing study posterior } \\
\text { versus anterior approach. }\end{array}$ \\
\hline Population (2) & $\begin{array}{l}\text { 18-year old or older individuals } \\
\text { undergoing primary THA. }\end{array}$ \\
\hline Intervention (3) & $\begin{array}{c}\text { Anterior, single-incision, } \\
\text { (modified-Heuter, Smith-Petersen) } \\
\text { Approach THA, Direct Anterior approach. }\end{array}$ \\
\hline Control (4) & $\begin{array}{l}\text { Posterior (Moore or Southern) Approach } \\
\text { THA, Posterolateral, MIS-posterior. }\end{array}$ \\
\hline Outcome measures (5) & $\begin{array}{l}\text { One quantifiable clinical outcome } \\
\text { measured by a validated score. }\end{array}$ \\
\hline
\end{tabular}

THA: total hip arthroplasty, MIS: minimally invasive surgery.

Two independent reviewers performed the quality assessment of included studies according to the Gradings of Recommendations Assessment, Development, and Evaluation (GRADE) approach. ${ }^{8}$ The risk of bias was assessed using the second version of the Risk-of-Bias (RoB 2) tool, ${ }^{9}$ based on five domains: (1) randomization process, (2) deviations from the intended interventions, (3) missing outcome data, (4) outcome measurement, and (5) selection of the reported result. Table 2 shows data related to the included studies.
Table 2. Data related to the included Studies.

Continuous Variables

Number of patients undergoing THA

Age

BMl

Functional outcome scores

Pain scores

Follow-up time

Operative time

Length of hospital stay

Surgeon's experience

Time for discontinuing walking aid

Postoperative opioid use

Categorical Variables

Gender

Major complications

Minor complications

Country of study

\section{Statistical analysis}

Continuous variables were extracted from the selected articles and expressed as means and standard deviations (SD), medians and ranges, or interquartile ranges (IQR). Data reported as medians and ranges or interquartile ranges were transformed into mean and SD according to the method described by Hozo et al. ${ }^{10}$ Pooled outcomes were expressed as weighted mean differences (WMD) or standardized mean differences (SMD) and 95\% confidence intervals $(\mathrm{Cl})$ using the inverse variance analysis and random effects model. Dichotomous variables including complications were extracted as absolute numbers for each cohort. Intraoperative fractures and postoperative dislocations were considered as major complications, whereas neuropraxia and deep vein thrombosis, ${ }^{11}$ hematoma, trochanteric bursitis, persistent pain, wound dehiscence, heterotopic ossification, superficial wound infection, and iliopsoas tendinopathy were considered as minor complications. Table 3 shows complications occurrence.

Heterogeneity $\left(\mathrm{I}^{2}\right)$ between the studies was assessed by the Cochran's $Q$ test, whereby a $p$-value $<0.05$ was considered statistically significant, and by Higgins $\mathrm{I}^{2}$ statistics, ${ }^{12}$ whereby an $\mathrm{I}^{2}$ value below $30 \%$ was considered as low heterogeneity; between $30 \%$ and $60 \%$ as moderate heterogeneity; and higher than $60 \%$ as substantial heterogeneity. The RevMan 5.3 software (Cochrane Community, London, UK) was used to create forest plots and display the effect size of each study together with the pooled result. ${ }^{13}$ Sources of heterogeneity for function (measured with Harris Hip Score - HHS) were investigated by subgroup analysis, to which case a new categorical covariate was created, named as short- and mid- to long-term. A follow-up period $<6$ months was categorized as short-term, while a follow-up period $\geq 6$ months was categorized as mid- to long-term. When deemed necessary, sensitivity analysis with recalculation of the pooled primary outcome was performed. Secondary outcomes included operative time, length of hospital stay, opioid use, pains scores, and time to discontinue any walking aid.

\section{RESULTS}

In total, 1882 eligible articles were identified in the database searches, 1810 of which were excluded after abstract and title screening. The remaining 72 articles underwent full-text reading for inclusion criteria, leading to a sample of nine peer-reviewed 
randomized control trials (RCTs) ${ }^{14-22}$ (Figure 1a and Table 2). After updating the literature search, one additional study (in press) was included. ${ }^{23}$ Thus, this meta-analysis included 10 peer-reviewed RCTs conducted with 774 patients, being 372 men and 402 women, of mean age ranging from 59 to 70.4 years, and mean body mass index (BMI) ranging from 24 to $31 \mathrm{~kg} / \mathrm{m}^{2}$. Of these, 385 were randomized to the posterior approach and 389 to the anterior approach. Maximum duration of follow-up ranged from six weeks to 60 months. Groups showed no significant differences regarding mean age and BMI, but two studies verified differences in gender distribution. ${ }^{18,23}$

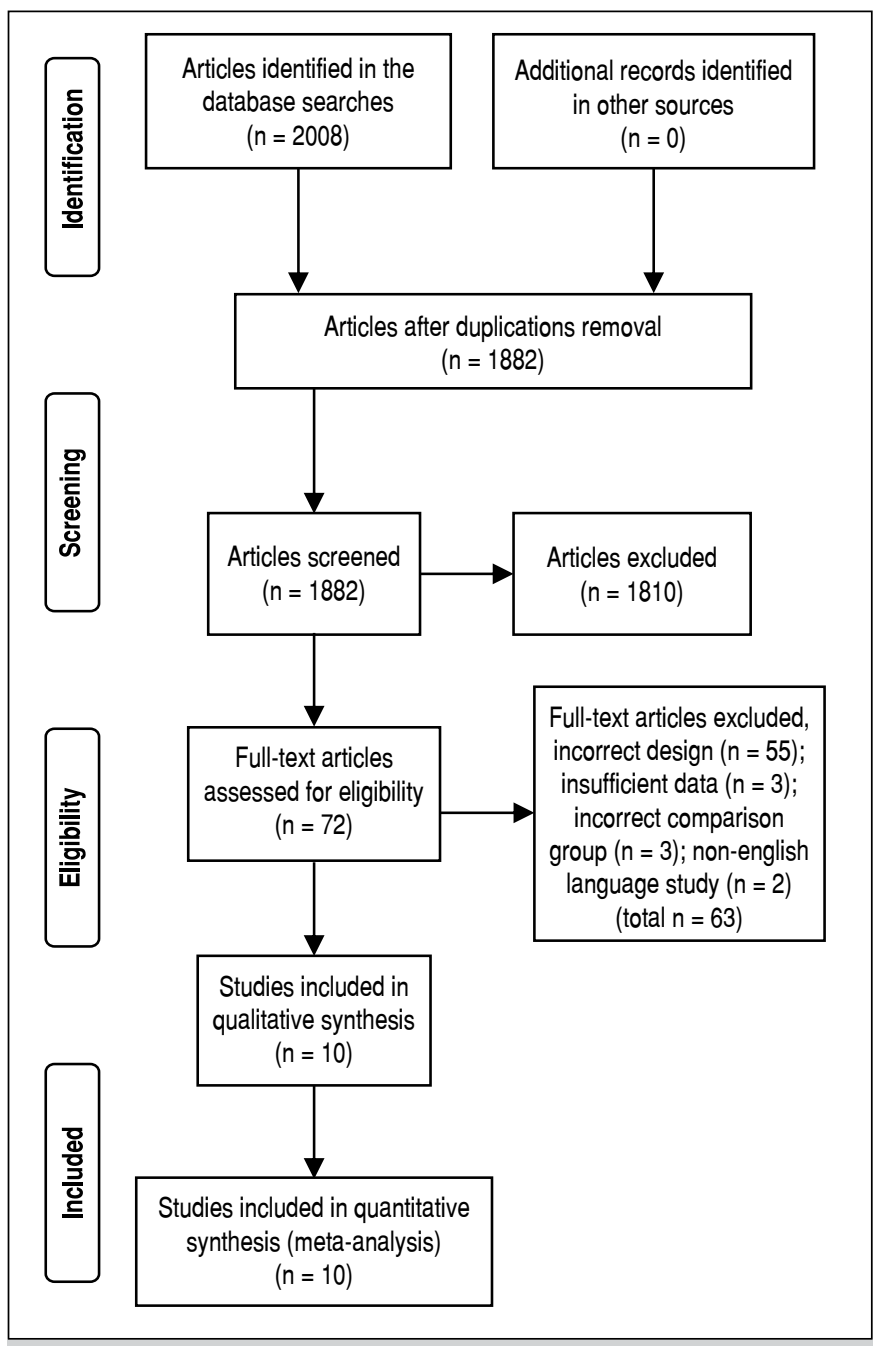

Figure 1a. PRISMA Flowchart.

\section{Risk of Bias and Quality of Evidence for Included Studies}

Two of the studies included in the meta-analysis presented a low risk of bias, whereas the other eight presented uncertain or high risk. The domains presenting higher risk of bias were "deviations from the intended intervention" and "outcome measurement" (Figure 1b). ${ }^{14-16,18-21}$ Seven studies informed that all procedures were performed by a single surgeon, six of which also reported that surgeons had sufficient experience for performing either posterior or anterior approach to total hip arthroplasty (THA). ${ }^{14-16,18,19,21,22}$ All studies showed low level of certainty for methodological quality based on the GRADE classification, whereas operative time and length of stay showed a high-quality level.

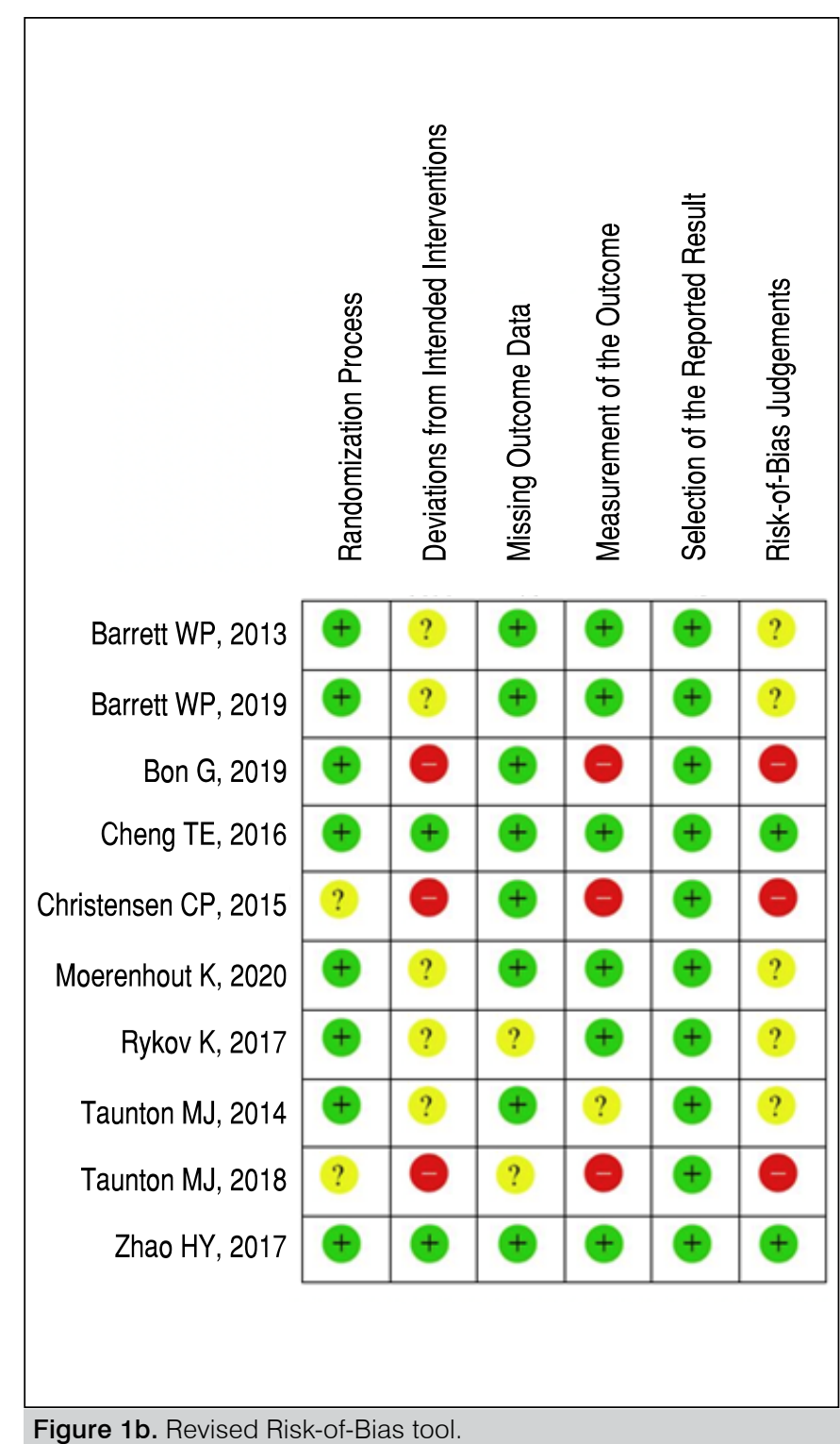

\section{Primary and secondary outcomes}

Although different scores were used to evaluate function (Table 3), eight of the ten studies adopted the Harris Hip Score (HHS) at six weeks and two, three, six, 12 and 60 months postoperatively. ${ }^{14-16,18,20-23}$ Patients who underwent the anterior approach to THA reached greater scores at the HHS in the short-term follow-up when compared to those who underwent the posterior approach (mean HHS $90.2 \pm 9.97$ versus $85.7 \pm 9.97$, respectively; WMD $4.06,95 \% \mathrm{Cl} 2.23$ to $5.88, \mathrm{I}^{2}=41 \%, \mathrm{p}<0.0001$ ), as well as in the mid- to long-term follow-up (mean HHS $93.9 \pm 8.81$ versus $92.5 \pm 9.71$, respectively; WMD $1.52,95 \% \mathrm{Cl} 0.48$ to $2.56, \mathrm{I}^{2}=0 \%$, $\mathrm{p}=0.004$; Figure 2).

Six studies reported the occurrence of major complications, ${ }^{14,17,18,21-23}$ being intraoperative fractures the most common, with 11 cases - five of which (45\%) occurred in the anterior approach and six (55\%) in the posterior approach (OR 0.83, 95\% $\mathrm{Cl} 0.25$ to $2.74, \mathrm{l}^{2}=42 \%, \mathrm{p}=0.76$ ). Postoperative dislocations occurred in five cases: three (60\%) in the posterior approach and two (40\%) in the anterior approach (OR $0.68,95 \% \mathrm{Cl} 0.12$ to 3.94 , $\left.\mathrm{l}^{2}=0 \%, p=0.66\right) .{ }^{17,18,21}$ 
Table 3. Summary of characteristics of included studies and primary outcomes

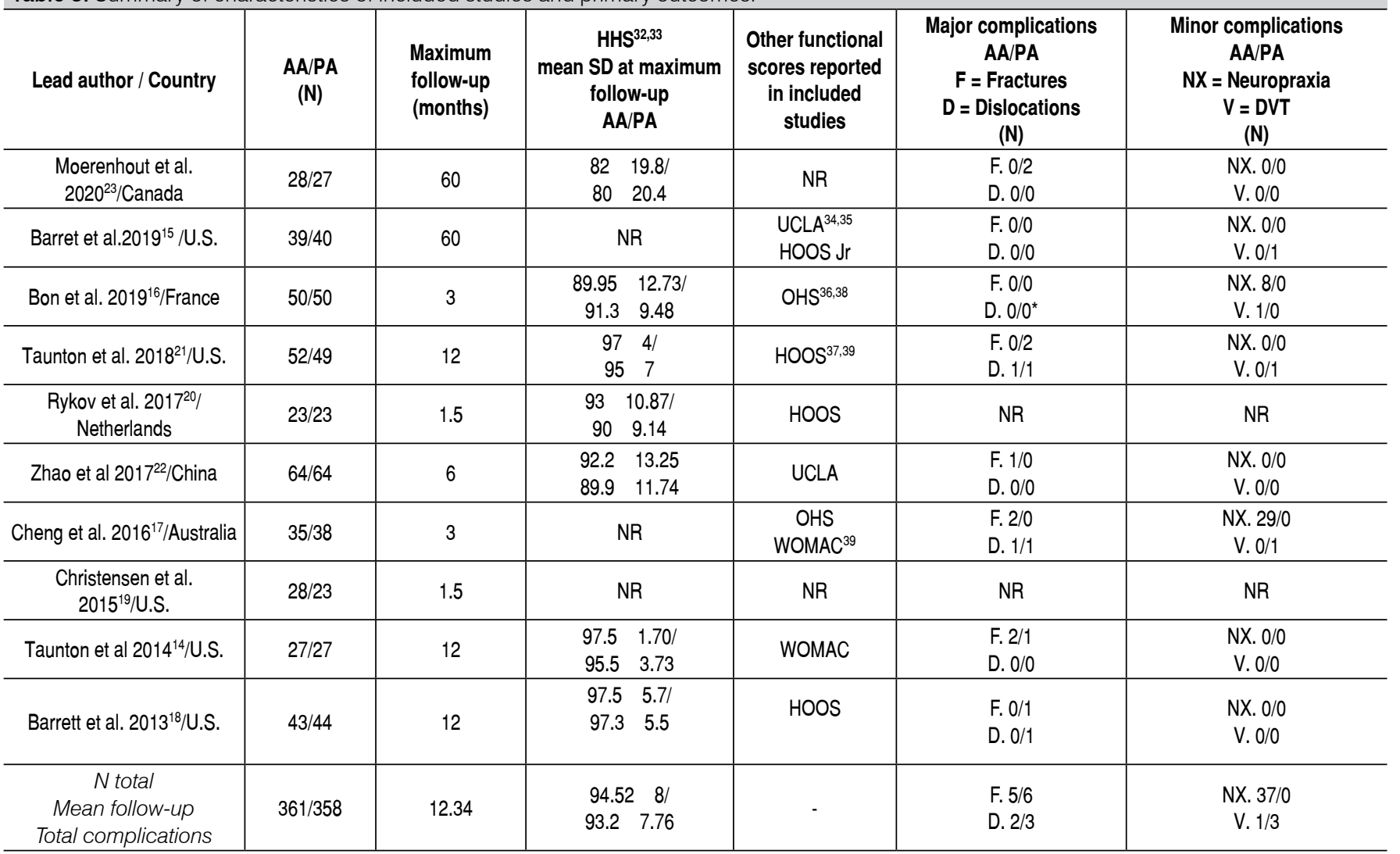

PA: posterior approach; AA: anterior approach; N: number of cases; NR: non-reported; SD: standard deviation; HHS: Harris Hip Score; UCLA: University of California Los Angeles Score; HOOS: Hip Disability and Osteoarthritis Outcome Score; OHS: Oxford Hip Score; WOMAC: Western Ontario and McMaster Universities Arthritis Index; * One case of traumatic hip dislocation after a fall was not included.

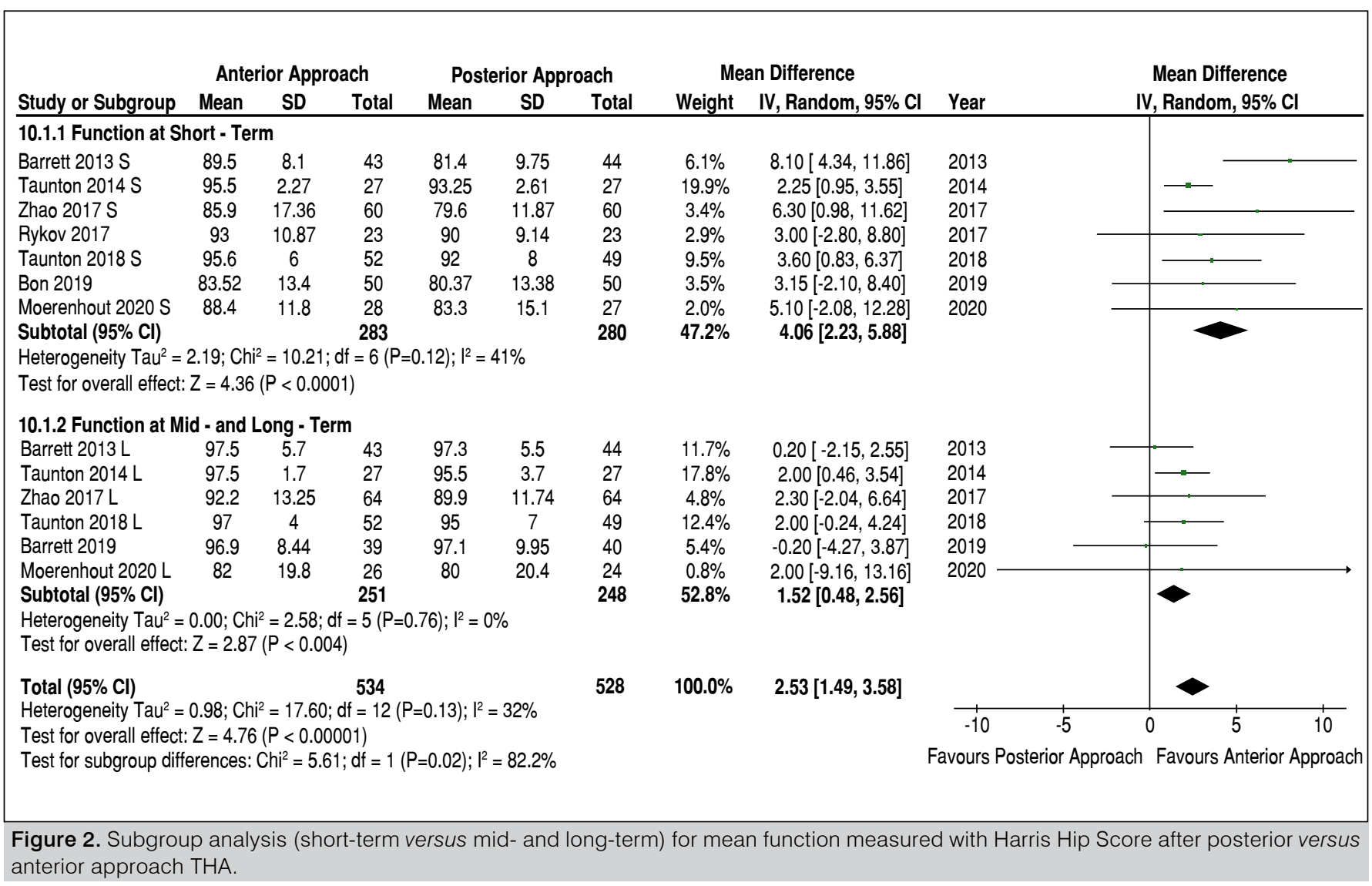


Five studies reported the occurrence of minor complications, ${ }^{15-18,21}$ being neuropraxia the most common - observed only in patients that underwent the anterior approach (37 cases) and involving only the lateral femoral cutaneous nerve (LFCN). ${ }^{16,17}$ In one study, most patients from the anterior approach group (29/35; $82 \%)$ presented with LFCN neuropraxia. ${ }^{17}$ Due to this particular high proportion, we performed a sensitivity analysis excluding this study, resulting in no differences between groups regarding the occurrence of all minor complications (OR 2.16, 95\% $\mathrm{Cl}$ 1.01 to $\left.4.63, \mathrm{I}^{2}=58 \%, \mathrm{p}=0.05\right) .{ }^{15,16,18,21}$ As shown in Table 3, four cases of deep vein thrombosis (DVT) were reported in the studies, three of which (75\%) occurred in the posterior approach and one (25\%) in the anterior approach (OR 0.52, 95\% Cl 0.05 to $\left.4.98, \mathrm{l}^{2}=25 \%, \mathrm{p}=0.57\right) \cdot{ }^{15,16,17,21}$

Seven studies included reports on operative time. ${ }^{16-18,20-23}$ When compared to the anterior approach, the mean operative time was shorter in patients undergoing the posterior approach (80.47 \pm 10.51 minutes versus $64.69 \pm 12.31$, respectively; mean of 15.98 minutes shorter, $95 \%$ $\mathrm{Cl} 11.2$ to $20.7, \mathrm{I}^{2}=87 \%, \mathrm{p}<0.00001$, Figure 3a). Eight studies reported length of hospital stay, ${ }^{16-23}$ indicating that hospital discharge was faster among patients submitted to the anterior approach when compared to those submitted to the posterior approach $(0.31$ days or 7.44 hours shorter for anterior approach, $95 \% \mathrm{Cl} 0.12$ to $0.51, \mathrm{l}^{2}=60 \%, \mathrm{p}=0.002$, Figure $3 b) .{ }^{16-23}$ Only four studies included reports on postoperative opioid intake, ${ }^{14,17,18,21}$ two of which verified a lower intake of opioids in early postoperative care among patients who underwent the anterior approach than among those who underwent the posterior approach (100 mg versus $145 \mathrm{mg}, \mathrm{p}=0.01 ; 300 \mathrm{mg}$ versus $413 \mathrm{mg}, \mathrm{p}=0.04$, respectively). ${ }^{17,21}$ Eight studies assessed postoperative pain, measured at time-points ranging from 24 hours to 24 months. ${ }^{14-18,21-23}$ However, due to the variability in pain scores, our meta-analysis included only three studies reporting pain as a component of the HHS ${ }^{14,16,18}$ and one study reporting pain as a component of the hip disability and osteoarthritis outcome score HOOS ${ }^{21}$.

Studies showed no difference regarding postoperative pain at short-term follow-up between the posterior and anterior approach (SMD $0.20,95 \% \mathrm{Cl}-0.01$ to $0.42, p=0.06$ ). Only three of the ten studies reported time for discontinuing walking aids, ${ }^{14,19,21}$ with shorter periods for patients from the anterior approach groups when compared to patients from the posterior approach group, with a mean difference of 9.8 days (33 versus 43 days, $\mathrm{p}=0.03 ; 23$ versus 35 days, $\mathrm{p}=0.04 ; 17$ versus 24 days, $p=0.04$, respectively)

\section{DISCUSSION}

Total hip arthroplasty (THA) is considered as one of the most important procedures in the field of Orthopaedic surgery; however, evidence on the most common approaches to this procedure still stirs controversies. Considering that, this study sought to investigate possible differences in the posterior and anterior approach to THA regarding functional and surgical outcomes by means of a systematic review and meta-analysis of randomized controlled trials (RCTs)

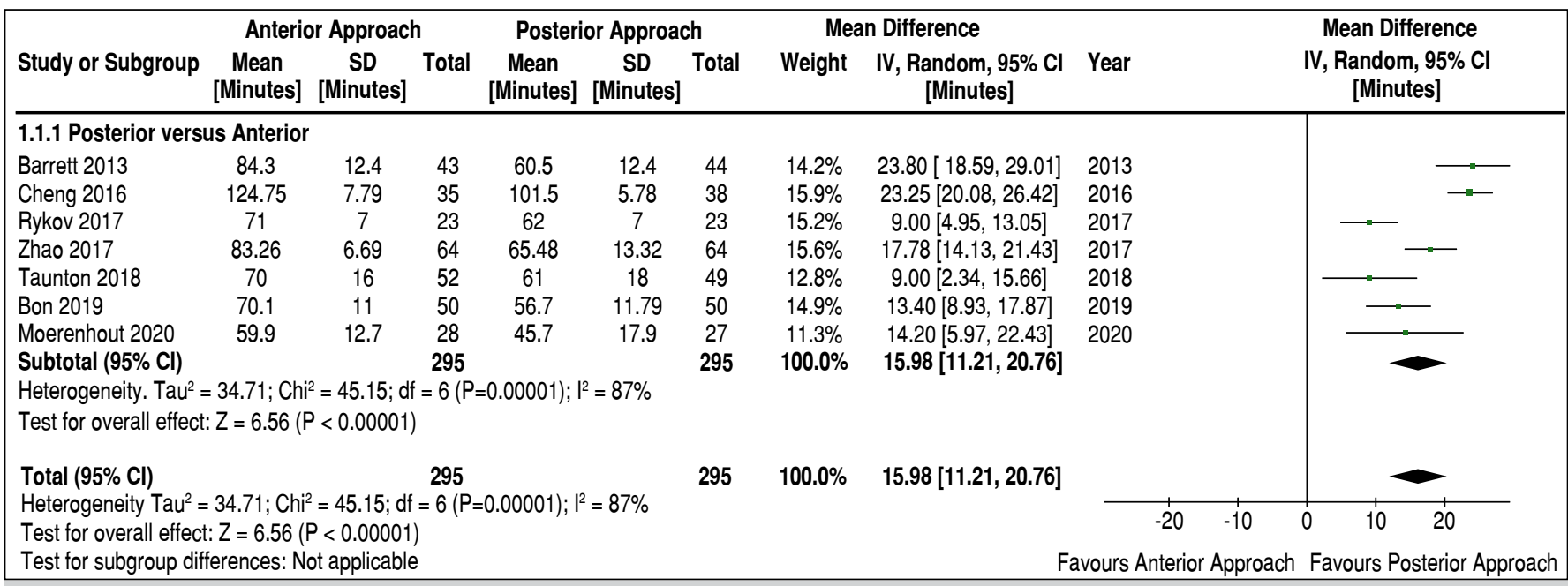

Figure 3a. Operative time during posterior versus anterior approach to THA.

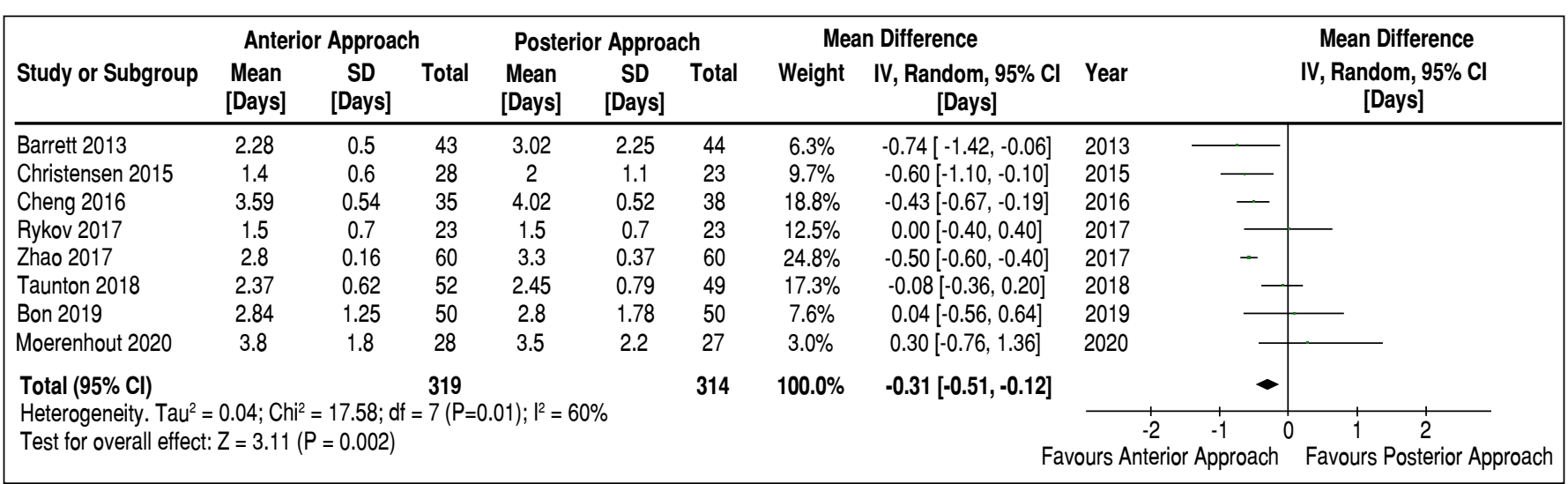

Figure 3b. Length of hospital stay for posterior versus anterior approach to THA. 
comparing these approaches. Our results indicate an association between shorter operative time and the posterior approach. We also verified no differences regarding complications arising from both procedures, including fractures and dislocations.

Several studies found the anterior approach to achieve superior clinical outcomes when compared with the posterior approach. ${ }^{18,22,23,25,27}$ In a systematic review of randomized and non-randomized studies comparing both approaches, Higgins et al. ${ }^{25}$ found that the anterior approach showed superior clinical outcomes at short-term follow-up in four studies. Conversely, Taunton et al. ${ }^{14}$ reported superior outcomes at early postoperative assessment following THA through the posterior approach when compared with the anterior approach, but no further differences in functional outcomes remained at 12 months after surgery. In comparison with the posterior approach, the anterior approach was associated with superior pooled HHS (mean of 4.06 points for short-term and 1.52 points for mid and long-term follow-up), but such difference did not reach the minimal 16-point clinical importance for the HHS. ${ }^{24}$ Thus, the clinical superiority attributed to the anterior approach over the posterior approach to THA remains unclear.

Corroborating our findings, one systematic review reported a similar rate of major complications for both approaches, including intraoperative fractures. ${ }^{26}$ A recent study found dislocations to be more prevalent among patients submitted to the posterior approach, with no differences in intraoperative fracture rates. ${ }^{40}$ Another systematic review on early postoperative complications following THA also reported no differences in complication rates between anterior and posterior approach. ${ }^{25}$ Regarding minor complications, one single cohort found high rates of LFCN neuropraxia in patients submitted to the anterior approach, ${ }^{17}$ which lead us to perform a sensitivity analysis for minor complications that showed no differences between the approaches. However, this specific analysis resulted in an underpowered comparison $(p=0.05)$.

The operative time was about 16 minutes shorter for the procedure performed through the posterior approach when compared with the anterior approach. Considering that a primary THA takes on average 100 minutes, with a standard deviation (SD) of 26 minutes, a difference of 16 minutes in operative time may represent a procedure 15 to $20 \%$ faster. ${ }^{27}$ As the posterior approach has historically been performed prior to the anterior approach, both surgery centers and surgeons may be more familiarized with its performance, indicating an expertise bias that favors this most traditional approach. Patients who underwent the anterior approach stayed in healthcare facilities 0.31 days (about eight hours) less than those who underwent the posterior approach. This may be explained by the fact that the surgical technique adopted in the anterior approach causes minimal muscle damage, thus allowing for a faster gait training and hospital discharge. ${ }^{29}$ Three studies reported that patients operated through the anterior approach were able to walk without the aid of crutches within a shorter period after surgery. ${ }^{14,19,21}$ However, the lack of sufficient knowledge on physical therapy protocols adopted during postoperative care hampers any strong inferences on this topic. Moreover, patients submitted to the anterior approach presented lower opioid intake, corroborating previous findings in the literature. ${ }^{30}$

Our initial plan was to compare the posterior with the anterior and the lateral approach. However, the database search identified only three RCTs comparing the posterior with the lateral approach, which would hinder most comparisons due to insufficient data. The heterogeneity and variability of clinical scores were yet another limitation inherent to this study, affecting the ability to pool several outcomes. Although the overall mean follow-up period was superior to 12 months, when considering RCTs individually, most studies have not completed a mid to long-term follow-up (more than six months). With that, we could not determine the complication rate at 12 months postoperatively. Most studies were conducted either in the U.S. or in Europe, which may preclude attempts to generalize our results. On the other hand, the inclusion of RCTs or Level 1 studies according to the Wright classification strengthens this systematic review. ${ }^{31}$ Whenever possible, we adopted robust methodologies and protocols to ensure accuracy in data acquisition and pooling.

\section{CONCLUSIONS}

This systematic review denoted the scarcity of high-quality studies comparing clinical and surgical outcomes between the posterior and anterior approach to total hip arthroplasty, possibly assisting surgeons and patients in determining the preferable surgical approach. The anterior approach was associated with a potential faster rehabilitation at short-term, higher functional scores, shorter length of hospitalization, and faster discontinuing of walking aids such as crutches and walkers. On the other hand, the posterior approach may provide shorter operative time, with no increase in complications rates and similar long-term function.

\section{ACKNOWLEDGEMENTS}

We would like to thank Brendan Higgins, MD for inspiration, Gilberto Nakama MD for support with the search strategy, Anis Rassi Jr. MD for statistical assistance and methodological consulting, and Grant Dornan MSc and Hugo Guedes MD for methodological consulting.

AUTHORS' CONTRIBUTIONS: Each author contributed individually and significantly to the development of this article. FL: writing and data analysis; FGG: writing and data analysis; MDA: article review and intellectual concept; AOR: article review; EB: article review; CM: article review; ADC: article review and intellectual concept.

\section{REFERENCES}

1. Chechik O, Khashan M, Lador R, Salai M, Amar E. Surgical approach and prosthesis fixation in hip arthroplasty world wide. Arch Orthop Trauma Surg. 2013;133(11):1595-600.

2. Waddell J, Johnson K, Hein W, Raabe J, FitzGerald G, Turibio F. Orthopaedic practice in total hip arthroplasty and total knee arthroplasty: results from the Global Orthopaedic Registry (GLORY). Am J Orthop (Belle Mead NJ). 2010;39(9 Suppl):5-13.

3. Smith-Petersen MN. Approach to and exposure of the hip joint for mold arthroplasty. J Bone Joint Surg Am. 1949;31A(1):40-6.

4. Moretti VM, Zachary DP. Surgical approaches for total hip arthroplasty. Indian J Orthop. 2017;51:368-76v.

5. Patel NN, Shah JA, Erens GA. Current trends in clinical practice for the direct anterior approach total hip arthroplasty. J Arthroplasty. 2019;34(9):1987-93.e3.
6. Higgins JPT, Green S. Cochrane handbook for systematic reviews of interventions. London: The Cochrane Collaboration; 2011.

7. Moher D, Liberati A, Tetzlaff J, Altman DG. PRISMA Group Preferred reporting items for systematic reviews and meta-analyses: the PRISMA statement. J Clin Epidemiol. 2009;62(10):1006-12.

8. Schünemann $\mathrm{H}$, Bro ek J, Oxman A, editors. GRADE handbook for grading quality of evidence and strength of recommendation. London: GRADE Working Group; 2009

9. Sterne JAC, Savovi J, Page MJ. RoB 2: a revised tool for assessing risk of bias in randomised trials. BMJ. 2019;366:14898.

10. Hozo SP, Djulbegovic B, Hozo I. Estimating the mean and variance from the median, range, and the size of a sample. BMC Med Res Methodol. 2005;5:13.

11. Hart A, Wyles CC, Abdel MP, Perry KI, Pagnano MW, Taunton MJ. Thirty-day major and minor complications following total hip arthroplasty-a 
comparison of the direct anterior, lateral, and posterior approaches. J Arthroplasty. 2019;34(11):2681-5.

12. Higgins JP, Thompson SG. Quantifying heterogeneity in a meta-analysis. Stat Med. 2002;21:1539-58.

13. The Nordic Cochrane Centre. Review Manager (RevMan) [Computer program] Version 5.2. Copenhagen: The Cochrane Collaboration; 2012.

14. Taunton MJ, Mason JB, Odum SM, Springer BD. Direct anterior total hip arthroplasty yields more rapid voluntary cessation of all walking aids: a prospective, randomized clinical trial. J Arthroplasty. 2014;29(9 Suppl):169-72.

15. Barrett WP, Turner SE, Murphy JA, Flener JL, Alton TB. Prospective, randomized study of direct anterior approach vs posterolateral approach total hip arthroplasty: a concise 5-year follow-up evaluation. J Arthroplasty. 2019;34(6):1139-42.

16. Bon G, Kacem EB, Lepretre PM, Weissland T, Mertl P, Dehl M, et al. Does the direct anterior approach allow earlier recovery of walking following total hip arthroplasty? A randomized prospective trial using accelerometry. Orthop Traumatol Surg Res. 2019;105(3):445-52.

17. Cheng TE, Wallis JA, Taylor NF, Holden CT, Marks P, Smith CL, et al. A prospective randomized clinical trial in total hip arthroplasty-comparing early results between the direct anterior approach and the posterior approach. J Arthroplasty. 2017;2(3):883-90.

18. Barrett WP, Turner SE, Leopold JP. Prospective randomized study of direct anterior vs postero-lateral approach for total hip arthroplasty. J Arthroplasty. 2013;28(9):1634-8

19. Christensen $C P$, Jacobs $C A$. Comparison of patient function during the first six weeks after direct anterior or posterior total hip arthroplasty (THA): a randomized study. J Arthroplasty. 2015;30(9 Suppl):94-7.

20. Rykov K, Reininga IHF, Sietsma MS, Knobben BAS, Ten Have BLEF. Posterolateral vs direct anterior approach in total hip arthroplasty (POLADA Trial): a randomized controlled trial to assess differences in serum markers. J Arthroplasty. 2017;32(12):3652-8.

21. Taunton MJ, Trousdale RT, Sierra RJ, Kaufman K, Pagnano MW. John Charnley Award: randomized clinical trial of direct anterior and miniposterior approach tha: which provides better functional recovery? Clin Orthop Relat Res. 2018;476(2):216-29.

22. Zhao HY, Kang PD, Xia YY, Shi XJ, Nie Y, Pei FX. Comparison of early functional recovery after total hip arthroplasty using a direct anterior or posterolateral approach: a randomized controlled trial. J Arthroplasty. 2017;32(11):3421-8

23. Moerenhout K, Derome P, Laflamme GY, Leduc S, Gaspard H, Benoit B. Direct anterior versus posterior approach for total hip arthroplasty: a multicentric prospective randomized clinical study. Can J Surg. 2020;63(5):E412-7.

24. Singh JA, Schleck C, Harmsen S, Lewallen D. Clinically important improvement thresholds for Harris Hip Score and its ability to predict revision risk after primary total hip arthroplasty. BMC Musculoskelet Disord. 2016;17:256.

25. Miller LE, Gondusky JS, Bhattacharyya S, Kamath AF, Boettner F, Wright J. Does surgical approach affect outcomes in total hip arthroplasty through 90 days of follow-up? A systematic review with meta-analysis. J Arthroplasty. 2018;33(4):1296-302.

26. Higgins BT, Barlow DR, Heagerty NE, Lin TJ. Anterior vs. posterior approach for total hip arthroplasty, a systematic review and meta-analysis. J Arthroplasty. 2015;30(3):419-34

27. Shah RP, Lauthen D, Geller JA, Cooper HJ. Average operative times for 1,313 primary total hip arthroplasty and 1,300 primary total knee arthroplasty over 39 months are roughly equal to medicare attributed operative times. J Arthroplasty. 2019;34(8):1553-6.

28. Meermans G, Konan S, Das R, Volpin A, Haddad FS. The direct anterior approach in total hip arthroplasty: a systematic review of the literature. Bone Joint J. 2017;99-B(6):732-40.

29. Bergin PF, Doppelt JD, Kephart CJ, Benke MT, Graeter JH, Holmes AS, et al. Comparison of minimally invasive direct anterior versus posterior total hip arthroplasty based on inflammation and muscle damage markers. J Bone Joint Surg Am. 2011;93(15):1392-8.

30. Seah S, Quinn M, Tirosh O, Tran P. Postoperative opioid consumption after total hip arthroplasty: a comparison of three surgical approaches. J Arthroplasty. 2019;34(11):2676-80.

31. Wright JG, Swiontkowski MF, Heckman JD. Introducing levels of evidence to the journal. J Bone Joint Surg Am. 2003;85-A(1):1-3.

32. Lieberman JR, Dorey F, Shekelle P, Schumacher L, Kilgus DJ, Thomas BJ, et al. Outcome after total hip arthroplasty: comparison of a traditional disease-specific and a quality-of-life measurement of outcome. J Arthroplasty. 1997;12(6):639-45.

33. Harris WH. Traumatic arthritis of the hip after dislocation and acetabular fractures: treatment by mold arthroplasty. An end-result study using a new method of result evaluation. J Bone Joint Surg Am. 1969:51.

34. Amstutz HC, Thomas BJ, Jinnah R, Kim W, Grogan T, Yale C. Treatment of primary osteoarthritis of the hip: a comparison of total joint and surface replacement arthroplasty. J Bone Joint Surg. 1984;66A:228.

35. Beaulé PE, Dorey FJ, Hoke R, Le Duff M, Amstutz HC. The value of patient activity level in the outcome of total hip arthroplasty. J Arthroplasty; 2006;21(4):547-55.

36. Murray DW, Fitzpatrick R, Rogers K, Pandit H, Beard DJ, Carr AJ, et al. The use of the Oxford Hip and Knee Scores. J Bone Joint Surg Br. 2007;89:1010-4.

37. Sariali E, Leonard P, Mamoudy P. Dislocation after total hip arthroplasty using Hueter anterior approach. J Arthroplasty. 2008;23(2):266-72.

38. Nilsdotter AK, Lohmander LS, Klässbo M, Roos EM. Hip disability and osteoarthritis outcome score (HOOS) - validity and responsiveness in total hip replacement. BMC Musculoskelet Disord. 2003;4:10.

39. Bellamy N, Buchanan WW, Goldsmith CH, Campbell J, Stitt LW. Validation study of WOMAC: a health status instrument for measuring clinically important patient relevant outcomes to antirheumatic drug therapy in patients with osteoarthritis of the hip or knee. J Rheumatol. 1988;15(12):1833-40.

40. Docter S, Philpott HT, Godkin L, Bryant D, Somerville L, Jennings M, et al Comparison of intra and post-operative complication rates among surgical approaches in Total Hip Arthroplasty: a systematic review and meta-analysis. J Orthop. 2020;20:310-25. 